\title{
Físico-química de variedades de acerola em dois estádios de maturação
}

\section{Physicochemical of acerola varieties in two stages of maturation}

\author{
Maria Ivaneide Ferreira Estevam ${ }^{1}$; Pahlevi Augusto de Souza ${ }^{2}$; Patricio Borges Maracajá ${ }^{3}$; Elisabeth Mariano Batista ${ }^{4}$ \\ Bianca Mara Reges.
}

Resumo: As áreas de plantios de aceroleiras para fins comerciais vêm aumentando progressivamente com a utilização da acerola pelas indústrias alimentícias e farmacêuticas. $\mathrm{O}$ objetivo do presente trabalho foi caracterizar física e quimicamente variedades de acerola em dois estádios de maturação. Frutos de cinco variedades (BV1, BV2, BV4, BV6 e C6P3), cultivadas no pomar experimental da Unidade de Ensino, Pesquisa e Extensão do Instituto Federal do Ceará (IFCE) foram colhidos nos estádios de maturação verde e maduro e avaliados. Estes frutos foram transferidos para o laboratório de Química de Alimentos do IFCE e submetidos à seleção (verde e maduro) para realização das análises físicas e químicas. Os frutos foram colocados em bandejas de isopor. O delineamento utilizado foi o DIC, constando de 5 tratamentos representados pelas 5 variedades de acerola, com 5 repetições de 10 frutos por parcela. Foram avaliadas: massa fresca, comprimento, diâmetro, sólidos solúveis (SS), acidez titulável (AT), pH, SS/AT e conteúdo de ácido ascórbico. As variedades apresentaram características físicas adequadas à industrialização. Os frutos de acerola da variedade BV2 em estádio de maturação verde e as variedades BV1 e BV4 em estádio de maturação maduro apresentaram maiores teores de ácido ascórbico. As variedades BV4 (estádio verde) e BV2 (estádio maduro) apresentaram maiores teores de sólidos solúveis e SS/AT.

Palavras-chaves: Malpighia emarginata D.C.; Frutos; Qualidade; Ácido ascórbico.

\begin{abstract}
Area with acerola plantations for commercial purposes have been increasing with the use of acerola by food industries and pharmaceutical companies. The objective of the present work was to characterize physically and chemically acerola varieties at two maturation stages. Acerola fruits of five varieties (BV1, BV2, BV4, BV6, and C6P3) grown in an experimental orchard of the Teaching, Research and Extension Unit of the Federal Institute of Education, Science and Technology of Ceará (IFCE) were harvested at the green and ripe stages for evaluation. These fruits were taken to the Food Chemistry Laboratory of the IFCE and subjected to selection (green and ripe) for physical and chemical analyses. The fruits were placed in polystyrene trays. A complete randomized experimental design was used, with five treatments (five acerola varieties), five replications, and 10 fruits per plot. The fresh weight, length, diameter, soluble solids (SS), titratable acidity (TA), pH, SS/TA ratio, and ascorbic acid content of the fruits were evaluated. The fruits presented adequate physical characteristics for industrialization. The acerola fruits of the BV2 variety at green stage, and BV1 and BV4 varieties at ripe stage had higher ascorbic acid contents. The varieties BV4 (green stage) and BV2 (ripe stage) had higher SS content and SS/TA ratio.
\end{abstract}

Key words: Malpighia emarginata D.C.; Fruits; Quality; Ascorbic acid.

\footnotetext{
*Autor para correspondência

Recebido para publicação em 26/04/2018; aprovado em 24/09/2018

${ }^{1}$ Especialista em Fruticultura Irrigada, Instituto Federal do Ceará Campus Limoeiro do Norte; Fone: (88) 999900103, E-mail: ivinferreira@ hotmail.com. ${ }^{2}$ Professor Doutor em Fitotecnia, Instituto Federal do Ceará, Limoeiro do Norte; Fone: (88) 992016473, E-mail: pahlevi10@ hotmail.com.

${ }^{3}$ Professor Doutor em Entomologia, Universidade Federal de Campina Grande, Paraíba; Fone: (83) 996173369, E-mail: patriciomaracaja@ gmail.com.

${ }^{4}$ Mestre em Tecnologia de Alimentos, Instituto Federal do Ceará Campus Limoeiro do Norte, Fone: (88) 999329261, E-mail: elisabethmariano@ hotmail.com.

${ }^{5}$ Mestranda em Tecnologia de Alimentos, Instituto Federal do Ceará Campus Limoeiro do Norte, Fone: (88) 992592549, E-mail: bianca-mara1@ outlook.com.
} 


\section{INTRODUÇÃO}

A acerola é conhecida no Brasil desde a década de 50, porém, seus cultivos ganharam expressão econômica a partir da década de 90, estando difundido praticamente em todo território nacional. O Brasil é considerado um dos maiores produtores, consumidores e exportadores de acerola do mundo. Entretanto, há maior predominância do cultivo nos estados do Nordeste, por suas características do solo e clima, necessárias para adaptação e desenvolvimento satisfatórios da acerola (OLIVEIRA; SOARES FILHO, 1998).

Destacam-se como produtores da região Nordeste os estados do Rio Grande do Norte, Pernambuco, Ceará, Paraíba e Bahia; o maior plantio de acerola encontra-se no município de Alhandra, seguido de Cabedêlo, Santa Rita, Sapé e Guarabira (CHAVES et al., 2004).

As condições edafoclimáticas brasileiras fazem com que as acerolas apresentem valores de sólidos solúveis (SS) de 5 a $12^{\circ}$ Brix, com média em torno de 7 a $8^{\circ}$ Brix (MUSSER et al., 2004). A relação entre sólidos solúveis (SS) e acidez titulável (AT) é um importante atributo de qualidade em acerolas, e uma forma usual para avaliar o sabor e selecionar a matériaprima para processamento. Esta relação aumenta em função da maturação do fruto, como resultado da elevação dos SS (SANTOS et al., 1999). O teor de ácido ascórbico também é utilizado como parâmetro pelas indústrias de transformação, as quais utilizam como padrões de referência para esse fruto o teor mínimo de $1200 \mathrm{mg}$ de ácido ascórbico por $100 \mathrm{~g}$ de polpa (MUSSER et al., 2004).

O teor de ácido ascórbico e outras características atribuídas à qualidade da acerola, tais como coloração, massa fresca e tamanho dos frutos, teor de sólidos solúveis e $\mathrm{pH}$ do suco, são afetadas pela falta de uniformidade genética dos pomares, e sofrem efeito de vários outros fatores, como precipitações pluviais, temperatura, altitude, adubação, irrigação e ocorrência de pragas e doenças (NOGUEIRA et al., 2002).

De acordo com Musser et al. (2004), o teor de ácido ascórbico, parâmetro básico utilizado na escolha de aceroleiras, assim como o de acidez titulável, de sólidos solúveis e pH, são influenciados pela posição geográfica, estádio de maturação do fruto, época de colheita e tratos culturais, além de fatores genéticos.

Entretanto, a variabilidade genética existente em acerola é um grave problema, uma vez que a maioria dos pomares é proveniente de propagação seminal, originando plantas com hábito de crescimento diferenciado e produção de frutos quantitativa e qualitativamente heterogêneos. Devido a esta variabilidade genética, os frutos provenientes de diferentes genótipos apresentam diferenças quanto a tamanho, coloração da casca e da polpa, composição físico-química, suculência, textura, aroma e sabor (RITZINGER et al., 2003). Assim, se faz necessária uma caracterização dos frutos em relação a cada região na qual as plantas estão disseminadas para avaliar frutos que apresentam atributos superiores, com consequentes vantagens na comercialização in natura e na agroindústria. Além do mais, esta variabilidade causa transtorno ao sistema de produção, dificulta a execução racional das práticas culturais e desorganiza, principalmente, o sistema de comercialização da propriedade (PÍPOLO et al., 2002).

Segundo Oliveira et al., (2009), a ocorrência desta variabilidade entre os genótipos cultivados nos pomares brasileiros pode ser explorada em programas de melhoramento vegetal, na seleção de indivíduos superiores ou como base para a geração de híbridos com características de interesse para o mercado consumidor, bem como na adaptação de genótipos às diversas regiões produtoras do país.

De acordo com Araújo e Minami (1994), o grande interesse comercial pela acerola foi despertado a partir da década de 40, quando se descobriu, na porção comestível da fruta altos teores de ácido ascórbico (vitamina C), sendo que esta concentração varia entre 1000 a $4676 \mathrm{mg}$ por $100 \mathrm{~g}$ de suco, aproximadamente 30 a 50 vezes superior àquela encontrada na laranja. A acerola também apresenta grandes quantidades de vitamina A, ferro, cálcio, além de açúcares e outras vitaminas que fazem parte do complexo B. Estas características desta cultura vêm aumentando progressivamente o interesse de produtores e indústrias alimentícias e farmacêuticas, que visam o aproveitamento comercial destes frutos.

Muito embora seja considerada uma cultura rentável, é fundamental a realização de pesquisas, na perspectiva de demonstrar não apenas resultados referentes à parte técnica (manejo da cultura), mas também de compreender por meio de análise, as especificidades dos fatores físico-químicos que, direta ou indiretamente, possam contribuir para uma melhor qualidade do fruto da aceroleira, aprimorando suas vantagens para produção, comercialização e para a agroindústria.

Dessa forma, o presente trabalho objetivou-se caracterizar física e quimicamente variedades de acerola em dois estádios de maturação.

\section{MATERIAL E MÉTODOS}

O experimento foi realizado com frutos do pomar experimental da Unidade de Ensino, Pesquisa e Extensão (UEPE), pertencente ao Instituto Federal de Educação, Ciência e Tecnologia do Ceará (IFCE), situado no Perímetro Irrigado Jaguaribe Apodi no Município de Limoeiro do Norte ( $\left.5^{\circ} 20^{\prime} \mathrm{S} ; 38^{\circ} 5^{\prime} \mathrm{O}\right)$. O clima da região é do tipo BSw’h', de acordo com a classificação de Koppën, com médias anuais de temperatura de $28,5^{\circ} \mathrm{C}$ a $35^{\circ} \mathrm{C}$, precipitação de $772 \mathrm{~mm}$, umidade relativa de $62 \%$, velocidade do vento de $7,5 \mathrm{~m} \mathrm{~s}^{-1}$, evapotranspiração de $3.215 \mathrm{~mm}$, e insolação de 3.030 horas ano $^{-1}$ (DNOCS, 2008).

Os frutos foram levados em caixas plásticas para o laboratório de Química de Alimentos do Instituto Federal de Educação, Ciência e Tecnologia do Ceará - IFCE, Campus Limoeiro do Norte, onde foram selecionados retirando-se frutos danificados e imperfeitos. Posteriormente, os frutos foram separados em lotes, quanto à coloração verde ou maduro, para realização das análises físicas e físico-químicas.

As características avaliadas foram: Massa Fresca: Determinou-se, pesando-se os frutos individualmente em balança semi-analítica (Marte BL3200H), com precisão de 0,01 g. Comprimento e Diâmetro dos Frutos: Utilizou-se medição direta do comprimento e diâmetro em 10 frutos, com emprego de paquímetro. Teor de Sólidos Solúveis (SS): Determinou-se por leitura em refratômetro digital (PR-100; Atago) com correção automática de temperatura (escala de 0 a 32\%), e os resultados expressos em ${ }^{\circ}$ Brix (IAL, 2008). Teor de Acidez Titulável (AT): Utilizou-se 1,0 mL de suco, diluída para $50 \mathrm{~mL}$ de água destilada, onde foi adicionado o 
indicador fenolftaleína e realizada a titulação com hidróxido de sódio $(\mathrm{NaOH})$ a $0,1 \mathrm{M}$ e os resultados expressos em gramas de ácido málico por $100 \mathrm{~g}$ de polpa (IAL, 2008). Potencial Hidrogeniônico (pH): Determinou-se o $\mathrm{pH}$ utilizando um potenciômetro digital com membrana de vidro, com o uso de uma amostra da polpa para acidez (AOAC, 2002). Relação SS/AT: Calculada através do quociente entre o teor de sólidos solúveis e acidez titulável. Ácido Ascórbico: Utilizou-se 5,0 mL da amostra do suco completando-se o volume para $50 \mathrm{~mL}$ em balão volumétrico com ácido oxálico $0,5 \%$. Em duplicata, foram retirados $5 \mathrm{~mL}$ e colocados em Erlenmeyer de $125 \mathrm{~mL}$, completando-se o volume para $50 \mathrm{~mL}$ com água destilada, titulou-se com a solução de Tillman, refrigerada, até o ponto de viragem levemente róseo permanente. Os resultados foram expressos em $\mathrm{mg}$ de vitamina $\mathrm{C}$ por $100 \mathrm{~g}$ de polpa (STROHECKER; HENNING, 1967).

O delineamento experimental inteiramente casualizado foi utilizado, consistindo de 5 tratamentos representados pelas variedades de acerola (BV1, BV2, BV4, BV6 e C6P3), com 5 repetições de 10 frutos por parcela.

Os dados obtidos foram submetidos à análise de variância (ANOVA), utilizando-se o Sistema de Análises Estatísticas e Genéticas da UFV (SAEG - UFV) e as médias foram comparadas pelo teste de Tukey a $5 \%$ de probabilidade.

\section{RESULTADOS E DISCUSSÃO}

Na Tabela 1, observa-se os valores médios das características físicas das cinco variedades de acerola nos dois estádios de maturação, verde e maduro, em que, mostraram-se diferentes significativamente para todos os fatores avaliados, que consistiram nos dois estádios de maturação, verde e maduro.

Para característica massa fresca, verificou-se que os frutos maduros apresentaram maiores valores médios em relação aos verdes, com exceção das variedades BV1 e BV4 (Tabela 1), demonstrando que os frutos atingiram seu desenvolvimento máximo quando maduros. Freire et al. (2006), avaliando frutos de acerola provenientes de diferentes pomares da Paraíba, encontraram valores médios de massa fresca variando entre 2,33 a 6,27 g. Franca (2016), avaliando 37 clones oriundos da Embrapa Agroindústria Tropical de Pacajús-CE, verificou em seu estudo que houve muita variação na massa dos frutos verdes, variando de 1,69 $\mathrm{g}$ a $4,33 \mathrm{~g}$, com amplitude de 2,64 g e média geral de 3,01 g. No presente trabalho, a massa fresca das variedades maduras variou de 6,3 a $9,48 \mathrm{~g}$.

Moscoso (1956) afirma que vários fatores podem alterar a massa fresca média dos frutos, podendo-se citar a irrigação, adubação, época de colheita, estádio de maturação, tratos culturais e o clima.

Os comprimentos variaram de 1,84 a $2,36 \mathrm{~cm}$ nos frutos verdes e de 2,02 a 2,28 cm nos frutos maduros (Tabela 1), com maiores valores para os frutos maduros, com exceção das variedades BV2 e BV4. Freire et al. (2006) encontraram valores de comprimento variando de 1,53 a 2,01 cm. Franca (2016) encontrou valores com variação de comprimento de 7,26 a 17,96 mm $(10,70 \mathrm{~mm})$ e média geral de $15,74 \mathrm{~mm}$ em frutos verdes.

Para o diâmetro dos frutos, foram encontrados valores variando de 2,02 a 2,47 cm nos frutos verdes e de 2,29 a 2,70 $\mathrm{cm}$ nos frutos maduros (Tabela 1), com maiores valores para os frutos maduros, com exceção da variedade BV4. Freire et al. (2006) encontraram valores de diâmetro variando de 1,66 a $2,32 \mathrm{~cm}$. Os resultados obtidos no presente trabalho estão de acordo ao intervalo de 1,0 a 4,0 cm proposto por Couceiro (1985). Estudos realizados por Franca (2016) mostraram que para o diâmetro a variação foi de 7,60 a 20,02 mm, com amplitude de 12,42 mm e média geral de 16,94 $\mathrm{mm}$ em frutos verdes.

Tabela 1: Características físicas de variedades de acerola em estádio de maturação verde e maduro.

\begin{tabular}{|c|c|c|c|c|c|c|}
\hline \multirow{3}{*}{ Variedades } & \multicolumn{6}{|c|}{ Características avaliadas } \\
\hline & \multicolumn{2}{|c|}{ Massa Fresca (g) } & \multicolumn{2}{|c|}{ Comprimento $(\mathrm{cm})$} & \multicolumn{2}{|c|}{ Diâmetro $(\mathrm{cm})$} \\
\hline & Verde & Maduro & Verde & Maduro & Verde & Maduro \\
\hline$\overline{B V 1}$ & 7,62 & 7,59 & 2,22 & 2,18 & 2,47 & 2,53 \\
\hline BV2 & 7,22 & 8,24 & 2,12 & 2,11 & 2,47 & 2,54 \\
\hline BV4 & 7,29 & 6,68 & 2,36 & 2,13 & 2,34 & 2,31 \\
\hline BV6 & 4,16 & 6,30 & 1,84 & 2,02 & 2,02 & 2,29 \\
\hline C6P3 & $5,18 *$ & 9,48 & 1,93 & 2,28 & 2,17 & 2,70 \\
\hline
\end{tabular}

*Média proveniente de 10 frutos.

Na Tabela 2 observa-se os valores médios e coeficiente de variação das características físico-químicas das cinco variedades de acerola para os frutos em estádio de maturação verde, provenientes de Limoeiro do Norte-CE.

Verificou-se para os teores de sólidos solúveis (SS) que os frutos verdes apresentaram menores valores variando de 6,34 a 6,80 ${ }^{\circ}$ Brix (Tabela 2). Segundo Alves (1996), os valores de SS, para acerolas do Nordeste, podem variar de 5 até um máximo de $12{ }^{\circ}$ Brix, sendo a média em torno de 7 a 8 ${ }^{\circ}$ Brix. De acordo com o mesmo autor, as exigências de SS para exportação é de no mínimo 7\% (Europa) ou 7,5\% (Japão). Conforme Lopes e Paiva (2002), para a indústria, os valores devem ser acima de $8 \%$, estando todas as variedades do presente trabalho abaixo da faixa recomendada. De acordo com Franca (2016) os teores de sólidos solúveis dos frutos em estádio verde, avaliados em seu estudo variaram de 6,06 a 10,56 ${ }^{\circ}$ Brix, com amplitude de 4,5 ${ }^{\circ}$ Brix e média geral de $7,53{ }^{\circ}$ Brix. dos solúveis dos frutos em estádio verde 10,56 ${ }^{\circ}$ Brix, com amplitude de $4,5{ }^{\circ}$ Brix e média geral de 7,53 ${ }^{\circ}$ Brix.

Esse aumento nos teores de sólidos solúveis pode ter sido ocasionado pelos processos de biossíntese, que no estádio maduro é maior, se comparado ao verde, ou pela degradação de polissacarídeos. Sabe-se que a acerola apresenta entre seus açúcares, glicose e frutose e quantidades mínimas de sacarose.

Não houve diferença significativa ao nível de 5\% de probabilidade no estádio verde para acidez titulável (Tabela 2) dos frutos de acerola. No entanto, em valores médios, verificou-se que ocorreu uma variação de 0,97 a 1,01\% de 
ácido málico, resultados próximos aos encontrados por Moura et al. (2007) avaliou acidez titulável em 45 clones de aceroleira provenientes de Limoeiro do Norte-CE, e encontraram uma média de $1,04 \%$ de ácido málico. Porém, Maciel et al. (2010) encontraram teores variando de 0,96 a $1,97 \%$ de ácido málico. Franca (2016) encontrou acidez de
0,90 a 2,07\% de ácido málico, com amplitude de 1,17\% e média geral de $1,53 \%$ de ácido málico em frutos verdes de 37 clones. De acordo com a Instrução Normativa $n^{\circ} 01$ de 07 de janeiro de 2000, a faixa mínima estabelecida para a acidez é de $0,80 \%$ de ácido málico, estando todas as variedades do presente trabalho fora da faixa contida na legislação.

Tabela 2: Características físico-químicas de variedades de acerola em estádio de maturação verde.

$$
\text { Variedades }
$$

\begin{tabular}{|c|c|c|c|c|c|c|c|}
\hline \multirow[b]{2}{*}{ Características avaliadas } & \multirow[b]{2}{*}{ BV1 } & \multirow[b]{2}{*}{ BV2 } & \multirow[b]{2}{*}{ BV4 } & \multirow[b]{2}{*}{ BV6 } & \multirow[b]{2}{*}{ C6P3 } & \multirow[b]{2}{*}{ Média } & \multirow[b]{2}{*}{$\begin{array}{l}\text { C.V } \\
(\%)\end{array}$} \\
\hline & & & & & & & \\
\hline Sólidos Solúveis $\left({ }^{\circ}\right.$ Brix $)$ & $6,34 \mathrm{~b}^{*}$ & $6,42 \mathrm{ab}$ & $6,80 \mathrm{a}$ & $6,44 \mathrm{ab}$ & $6,72 \mathrm{ab}$ & 6,54 & 3,64 \\
\hline Acidez Titulável (\% de ácido málico) (AT) & $1,01^{\mathrm{NS}^{* *}}$ & $0,98^{\mathrm{NS}}$ & $1,01^{\mathrm{NS}}$ & $0,97^{\mathrm{NS}}$ & $0,97^{\mathrm{NS}}$ & 0,99 & 6,73 \\
\hline $\mathrm{pH}$ & $3,45 \mathrm{~b}$ & $3,37 \mathrm{c}$ & $3,09 \mathrm{~d}$ & $3,34 \mathrm{c}$ & 3,63 a & 3,38 & 0,95 \\
\hline SS/AT & $6,29 \mathrm{a}$ & $6,57 \mathrm{a}$ & $6,74 \mathrm{a}$ & $6,63 \mathrm{a}$ & $6,94 \mathrm{a}$ & 6,63 & 6,87 \\
\hline Vitamina $\mathrm{C}\left(\mathrm{mg} 100 \mathrm{~g}^{-1}\right)$ & $1454,2 \mathrm{~b}$ & 1616 a & $1482,1 \mathrm{~b}$ & $907,4 \mathrm{c}$ & $810,4 \mathrm{c}$ & 1254,0 & 4,04 \\
\hline
\end{tabular}

* Médias seguidas das mesmas letras nas linhas não diferem entre si pelo Teste de Tukey a 5\% de probabilidade.

** Não significativo.

Com relação aos valores médios de $\mathrm{pH}$ para as variedades estudadas, ocorreu uma variação entre 3,09 (BV4) e 3,63 (C6P3) para as variedades em estádio de maturação verde (Tabela 2). Musser et al. (2004), verificaram $\mathrm{pH}$ variando de 3,10 a 3,46. Os valores de $\mathrm{pH}$ encontrados por Franca (2016) dos frutos avaliados em estádio verde variaram de 3,39 a 3,85, com amplitude de 0,46 e média geral de 3,58, ou seja, estão semelhantes aos encontrados no presente estudo. No processo de maturação dos frutos há síntese de sólidos solúveis e diminuição de ácidos pelo processo de respiração (CHITARRA; CHITARRA, 2005). De acordo com a Instrução Normativa $\mathrm{n}^{\circ} 01$ de 07 de janeiro de 2000, para a produção de polpa o valor mínimo de $\mathrm{pH}$ é de 2,8 para industrialização, e não é especificado um valor máximo para o mesmo, estando todas as variedades estudadas de acordo com essa faixa.

Para a relação SS/AT, as variedades em estádio de maturação verde (Tabela 2), os valores não diferiram estatisticamente, porém, em valores médios, variaram de 6,29 a 6,94 para as variedades BV1 e C6P3, respectivamente. Deste modo, pode-se verificar que os valores desta relação estão baixos em relação aos valores dos frutos maduros, significando assim, que o fruto não está em bom grau de maturação para consumo in natura. França e Narain (2003) relataram valores de SS/AT para três matrizes de acerola de 4,73 a 9,42. Valores médios similares ao do presente estudo foram encontrados por Franca (2016), em seu estudo com 37 clones de aceroleira provenientes de Pacajús-CE, onde encontrou uma variação entre 3,17 e 8,31, com amplitude de 5,14 e média geral de 5,06 com frutos verdes.

Os teores de ácido ascórbico variaram de 810,4 a 1616,02 mg de ácido ascórbico por $100 \mathrm{~g}$ de polpa nos frutos verdes entre as cinco variedades de acerola (Tabela 2 ). No entanto, pode-se verificar que a variedade BV2, com o valor de $1616,02 \mathrm{mg}$ de ácido ascórbico por $100 \mathrm{~g}$ de polpa, apresentou maior teor, sendo considerada mais adequada para o mercado de processamento por apresentar maior teor dessa vitamina. Em relação aos estádios de maturação, foram encontrados maiores teores de ácido ascórbico nos frutos verdes. A variedade BV2 apresentou a maior redução nos teores de ácido ascórbico com percentual de perda de 48,0\%. Musser et al. (2004), avaliando as características físicoquímicas dos primeiros 12 genótipos do Banco Ativo de Germoplasma da Universidade Federal Rural de Pernambuco (UFRPE), relataram que a variação média do teor de ácido ascórbico foi de 1067 a $1846 \mathrm{mg} .100 \mathrm{~g}^{-1}$ de polpa. Maciel et al. (2010), caracterizando genótipos de aceroleira, encontraram teores de 750 a $1.678 \mathrm{mg} .100 \mathrm{~g}^{-1}$ de polpa. Franca (2016) estudou 37 clones de aceroleira e verificou que os teores de ácido ascórbico variaram de $1.375,95$ a 3.125,10 mg. $100 \mathrm{~g} \mathrm{~g}^{-1}$, com amplitude de $1.749,15 \mathrm{mg} .100 \mathrm{~g}^{-1}$ e média geral de $2.458,77 \mathrm{mg} .100 \mathrm{~g}^{-1}$ em frutos verdes. De acordo com a Instrução Normativa $\mathrm{n}^{\circ} 01$ de 07 de janeiro de 2000, o mínimo exigido para comercialização como polpa é de 800 mg por $100 \mathrm{~g}$ de polpa, estando todas as variedades em estádio de maturação verde do presente trabalho dentro dessa faixa mínima exigida.

Asenjo et al. (1960) verificaram que a atividade enzimática nos frutos verdes é menor que nos frutos maduros, fato que pode explicar as perdas encontradas no decorrer da maturação.

Na Tabela 3, observa-se os valores médios e coeficiente de variação das características físico-químicas das cinco variedades de acerola para os frutos em estádio de maturação maduro, provenientes de Limoeiro do Norte-CE.

Tabela 3: Características físico-químicas de variedades de acerola em estádio de maturação maduro.

\begin{tabular}{|c|c|c|c|c|c|c|c|}
\hline \multirow{2}{*}{ Características avaliadas } & \multicolumn{6}{|c|}{ Variedades } & \multirow[b]{2}{*}{$\begin{array}{l}\text { C.V } \\
(\%)\end{array}$} \\
\hline & BV1 & BV2 & BV4 & BV6 & C6P3 & Média & \\
\hline Sólidos Solúveis ( ${ }^{\circ}$ Brix) $(\mathrm{SS})$ & $7,34 \mathrm{ab}$ & $7,48 \mathrm{a}$ & $7,12 \mathrm{ab}$ & $6,32 \mathrm{c}$ & $7,02 \mathrm{~b}$ & 7.06 & 3,64 \\
\hline Acidez Titulável (\% de ácido málico) (AT) & $1,00^{\mathrm{NS} * *}$ & $0,98^{\mathrm{NS}}$ & $1,02^{\mathrm{NS}}$ & $0,97^{\mathrm{NS}}$ & $0,97^{\mathrm{NS}}$ & 0,99 & 6,73 \\
\hline $\mathrm{Ph}$ & $3,47 \mathrm{~b}$ & $3,23 \mathrm{c}$ & $3,21 \mathrm{c}$ & $3,22 \mathrm{c}$ & $3,59 \mathrm{a}$ & 3,34 & 0,95 \\
\hline SS/AT & $7,31 \mathrm{ab}$ & $7,63 \mathrm{a}$ & $7,00 \mathrm{ab}$ & $6,49 \mathrm{~b}$ & $7,19 \mathrm{ab}$ & 7,12 & 6,87 \\
\hline Vitamina $\mathrm{C}\left(\mathrm{mg} 100 \mathrm{~g}^{-1}\right)$ & $987,3 \mathrm{a}$ & $841,5 \mathrm{~b}$ & $1087,4 \mathrm{a}$ & $731,4 \mathrm{c}$ & $530,6 \mathrm{~d}$ & 835,6 & 4,04 \\
\hline
\end{tabular}

* Médias seguidas das mesmas letras nas linhas não diferem entre si pelo Teste de Tukey a 5\% de probabilidade. 
** Não significativo.

Verificou-se que os teores de sólidos solúveis para os frutos do estádio maduro apresentaram maiores teores que variaram entre 6,32 e $7,48{ }^{\circ}$ Brix (Tabela 3 ), ao contrário dos teores, para a mesma característica, obtidos para os frutos no estádio verde.

De acordo com os resultados, variedades BV1, BV2 e BV4, no estádio de maturação maduro, apresentaram os maiores teores de sólidos solúveis, sendo, portanto, provavelmente consideradas mais aceitas para o consumo "in natura". Esse aumento é provavelmente ocasionado pelos processos de biossíntese ou pela degradação de polissacarídeos (KAYS, 1991). Salunkhe e Desai (1984) afirmam que a acerola apresenta entre seus açúcares, glicose e frutose e quantidades mínimas de sacarose.

Os SS têm sido utilizados como índice de maturidade para algumas frutas, porém seus teores podem ser reduzidos devido sofrer efeito de alguns fatores como chuvas ou irrigação excessiva, em virtude da diluição do suco celular, podendo variar também de acordo com o genótipo. Segundo Dhillon; Singh e Kundal, (1990) as temperaturas médias elevadas e a alta luminosidade podem aumentar os SS, em razão da maior atividade fotossintética e maior acúmulo de carboidratos nos frutos. Gomes et al. (2000) encontraram valores médios situados entre 5,25 e 8,58\%, cuja variação foi relativa aos genótipos estudados.

Não houve diferença significativa ao nível de 5\% de probabilidade para acidez titulável no estádio maduro dos frutos de acerola. No entanto, em valores médios, verificou-se que ocorreu uma variação de 0,97 a 1,02\% de ácido málico (Tabela 3).

Segundo Kays (1991), os ácidos orgânicos contribuem para a acidez e o aroma característico dos frutos. As frutas tropicais, em sua maioria, apresentam uma diminuição nos teores desses ácidos com o amadurecimento, isto devido à utilização destes no ciclo de Krebs, durante o processo respiratório e como fonte de carbono para a síntese de açúcares. $\mathrm{O}$ estado de conservação de frutas pode ser avaliado pela acidez, sendo importante característica em relação ao sabor, juntamente com os valores de sólidos solúveis.

Com relação aos valores médios de $\mathrm{pH}$ para as variedades estudadas, ocorreu uma variação nas variedades maduras com valores de 3,21 (BV4) a 3,59 (C6P3) (Tabela 3). De acordo com Nogueira et al. (2002), com o avanço da maturação, a acerola fica menos ácida, aumentando assim seu $\mathrm{pH}$. Os mesmos autores verificaram $\mathrm{pH}$ variando de 3,36 a 3,80 . Os resultados encontrados no presente trabalho estão próximos aos valores encontrados por Maciel et al. (2010) e França e Narain (2003), cuja variação foi de 2,9 a 3,5 e 3,18 a 3,53 , respectivamente. No entanto, o $\mathrm{pH}$ é um parâmetro de variabilidade em acerolas, mesmo nas maduras.

As variedades de acerola em estádio de maturação maduro (Tabela 3) apresentaram maiores valores médios de SS/AT, com máximo de 7,63 para a variedade BV2. Significando que os frutos estão em bom grau de maturação, pois esse grau aumenta quando há decréscimo de acidez e alto conteúdo de SS, decorrentes da maturação (CHITARRA; CHITARRA, 2005). Musser et al. (2004), em sua pesquisa de caracterização dos primeiros 12 genótipos de aceroleiras, constataram valores de SS/AT variando entre 4,27 e 7,31. Já Maciel et al. (2010) encontraram valores entre 3,79 (PL38) e 7,06 (PL34).
Contudo, a variedade BV2 em estádio maduro, caracteriza-se com doçura maior que as demais variedades, sendo que durante a maturação dos frutos a relação SS/AT tende a aumentar os valores, facilitando até mesmo o ponto de colheita. As variedades estudadas que apresentaram boa relação SS/AT se mostraram com baixos teores de vitamina $\mathrm{C}$, que pode ser explicado, em parte, pelo fato de ocorrer uma relação direta entre o teor de acidez titulável e o teor de vitamina $\mathrm{C}$ em frutos de acerola.

Os teores de ácido ascórbico nos frutos maduros variaram de 530,6 a 1087,4 mg de ácido ascórbico por $100 \mathrm{~g}$ de polpa entre as cinco variedades de acerola (Tabela 3 ). No entanto, pode-se verificar que as variedades BV1 e BV4, com os valores de 987,3 e 1087,4 mg de ácido ascórbico por $100 \mathrm{~g}$ de polpa, apresentaram o maior teor desse ácido. Em relação aos estádios de maturação, a variedade BV6 apresentou a menor redução nos teores de ácido ascórbico quando os frutos amadureceram, com percentual de perda 19,4\%.

Os resultados encontrados no presente trabalho, para as acerolas no estádio maduro, estão abaixo dos resultados verificados por Musser et al. (2002), que caracterizando acerolas maduras encontraram teor de ácido ascórbico variando de $1.066,66$ a $1.845,79 \mathrm{mg} 100 \mathrm{~mL}^{-1}$ de polpa. Caracterizando três variedades de acerola, França e Narain (2003) relataram, para frutos maduros, valores de 940 a 2000 $\mathrm{mg}$ por $100 \mathrm{~g}$ de polpa. Enquanto, Mezadri et al. (2008), encontraram valores de ácido ascórbico entre 632 e 920 mg. $100 \mathrm{~g}^{-1}$ de polpa em acerolas maduras do Distrito de Itajaí - SC. Segundo o IBRAF (1995), o teor de ácido ascórbico mínimo aceito pelas indústrias é de $1200 \mathrm{mg}$ de ácido ascórbico por $100 \mathrm{~g}$ de polpa, sendo que no presente trabalho, apenas as variedades BV1, BV2 e BV4 se enquadram nesse padrão quando no estádio verde. Acerolas destinadas à exportação para a Europa e Japão, devem conter o mínimo de $1000 \mathrm{mg}$ de ácido ascórbico. $100 \mathrm{~g}^{-1}$ de polpa (ALVES, 1996).

Maciel et al. (2010) afirmam que o teor de vitamina C na acerola pode ser influenciado por vários fatores como a localização geográfica, práticas de cultivo, regime pluvial, exposição à luz do sol, características genéticas e, principalmente, o estádio de maturação em que os frutos se encontram, com maiores teores de vitamina $\mathrm{C}$ nos frutos verdes.

\section{CONCLUSÕES}

As variedades de acerolas apresentaram características físicas adequadas à industrialização. Em relação às características químicas as variedades de acerola BV2 em estádio de maturação verde, e as variedades BV1 e BV4 em estádio de maturação maduro, apresentaram maiores teores de ácido ascórbico, estando dentro da faixa exigida pelas indústrias de processamento.

\section{REFERÊNCIAS}

ALVES, R. E. Características das frutas para exportação. In: GORGATTI NETTO, A. Acerola para exportação: procedimentos de colheita e pós colheita. Brasília: EMBRAPA-SPI, 1996. (Série Publicações Técnicas Frupex, 21). 
ARAÚJO, P. S. R. de.; MINAMI, K. Acerola. Campinas: Fundação Cargill, 1994.

ASENJO, C. F.; PENALOZA, A.; MEDINA, P. Characterization of ascorbase present in the fruit of the Malpighia punicifolia L. Federation of American Societies for Experimental Biology. Federation Proceedings, Bethesda, v. 19 , n. 1,1960

ASSOCIATION OF OFFICIAL ANALYTICAL CHEMISTRY. 2002. Official methods of analysis of the Association of Official Analytical Chemistry. 17. ed. Washington: AOAC.

BRASIL. Ministério da Saúde. Secretaria da Vigilância Sanitária. Portaria n ${ }^{\circ} 216$, de 15 de setembro de 2004. Aprova o regulamento técnico de boas práticas para serviços de alimentação. Diário Oficial da União; Poder Executivo, 2004.

CHAVES, M. da C. V; GOUVEIA, J. P. G.; ALMEIDA, F. de A. C.; LEITE, J. C. A.; SILVA, F. L. H. Caracterização físico-química do suco de acerola. Revista de Biologia e Ciências da Terra, v. 4, n. 2, 2004.

CHITARRA, M. I. F.; CHITARRA, A. B. Pós-colheita de frutos e hortaliças: Fisiologia e Manuseio. 2 ed, Lavras: UFLA, 2005.

COUCEIRO, E. M. Curso de extensão sobre o cultivo da acerola. Recife: UFRPE, 1985.

DHILLON, B. S.; SINGH, S. N.; KUNDAL, G. S. Studies on the developmental physiology of guava fruit (Psidium guajava L.): II. Biochemical Characters. Punjab Horticultural Journal, Chandigarh, v. 27, n. 3/4, 1990.

DNOCS, DEPARTAMENTO NACIONAL DE OBRAS CONTRA AS SECAS. Perímetro Irrigado Jaguaribe-Apodi. 2008. Disponível em: <http://www.inovagri.org.br/revista/index.php/rbai/article/vie wFile/55/pdf_48> Acesso em: 20 de Junho de 2015.

FRANCA, L. G. da; Indicação de clones de acerola visando a qualidade de frutos verdes para processamento. 2016 . 96 fls. Dissertação (Mestrado em Tecnologia de Alimentos) Instituto Federal de Educação, Ciência e Tecnologia do Ceará, Limoeiro do Norte - CE, 2016.

FRANÇA, V. C.; NARAIN, N. Caracterização química dos frutos de três matrizes de acerola (Malpighia emarginata). Ciência e Tecnologia de Alimentos, v. 23, n. 2, 2003.

FREIRE, J. L. O.; LIMA, A. N.; SANTOS, F. G. B.; MARINUS, J. V. M. L. Características físicas de frutos de acerola cultivada em pomares de diferentes microrregiões do estado da Paraíba. Agropecuária Técnica, v. 27, n. 2. 2006.

GOMES, E.; DILERMANDO, P.; MARTINS, A. B. G.; FERRAUDO, A. S. Análise de grupamentos e de componentes principais no processo seletivo em genótipos de aceroleira (Malpighia emarginata D.C). Revista Brasileira de Fruticultura, Jaboticabal, v. 22, n. 1, 2000.
IBRAF, INSTITUTO BRASILEIRO DE FRUTAS. Soluções fruta a fruta: acerola. $2^{\mathrm{a}}$ ed São Paulo, 1995.

INSTITUTO ADOLFO LUTZ. Normas analíticas, métodos químicos e físicos de alimentos. 4.ed. 1ed. digital. São Paulo: IAL: 2008.

KAYS, S. J. Postharvest physiology of perishable plant products. New York: Van Nostrand Reinhold, 1991.

LOPES, R.; PAIVA, J. R. Aceroleira. In: BRUCKNER, C.H. (Ed). Melhoramento de fruteiras tropicais. Viçosa, MG: UFV, 2002.

MACIEL, M. I. S; MELO, E. LIMA, V.; SOUZA, K. A.; SILVA, W. Caracterização físico-química de frutos de genótipos de aceroleira (Malpighia emarginata D.C.), Revista Ciência e Tecnologia de Alimentos, Campinas, v.30, n.4, 2010.

MEZADRI, T.; VILLAÑO, D.; FERNÁNDEZPACHÓN, M. S.; GARCÍA-PARRILlA, M. C.; TRONCOSO, A. M. Antioxidant compounds and antioxidant activity in acerola (Malpighia emarginata DC.) fruits and derivatives. Journal of Food Composition and Analysis, v. 21, n. 4, 2008.

MOSCOSO, C.G. West Indian Cherry: Richest known source of natural vitamin C. Economic Botany, v.10, n.3, 1956.

MOURA, C. F. H.; ALVES, R. E.; FIGUEIREDO, R. W.; PAIVA, J. R. Avaliações físicas e físico-química de frutos de clones de aceroleira (Malpighia emarginata D. C.). Revista Ciência Agronômica, Fortaleza, v. 38, n. 1, 2007.

MUSSER, R. S.; LEMOS, M. A.; LIMA, V. L. A. G.; MELO, E. A.; LEDERMAN, I. E.; SANTOS, V. F. Análise conjunta das características físico-químicas de acerola (Malpighia emarginata D.C.) do banco ativo de germoplasma em Pernambuco. In: CONGRESSO BRASILEIRO DE FRUTICULTURA, 17, 2002, Belém. Os novos desafios da fruticultura brasileira, Anais. Belém: SBF, 2002. CD-ROM.

MUSSER, R. S.; LEMOS, M. A.; LIMA, V. L. A. G.; MELO, E. A.; LEDERMAN, I. E.; SANTOS, V. F. Características físico-químicas de acerola do banco ativo de germoplasma em Pernambuco. Ciência e Tecnologia de Alimentos, v. 24, n. 4, 2004.

NOGUEIRA, R. J. M. C.; MORAES, J. A. P. V.; BURITY, H. A.; SILVA JUNIOR, J. F. Efeito do estádio de maturação dos frutos nas características físico-químicas de acerola. Pesquisa Agropecuária Brasileira, Brasília, v.37, n.4, 2002.

OLIVEIRA, J. R. P., SOARES FILHO, W. S. Situação da cultura da acerola no Brasil e ações da Embrapa Mandioca e Fruticultura em recursos genéticos e melhoramento. In: Simpósio de Recursos Genéticos e Melhoramento de Plantas para o Nordeste do Brasil, 1998, Petrolina, Anais. Petrolina: EMBRAPA Semi-Árido, 1998.

OLIVEIRA, M. G; OLIVEIRA, J. G; FILHO, A. G; PEREIRA, M. G; VIANA, A. P.; FILHO, G. A. S.; LOPES, G. E. M.; Diversidade genética de aceroleiras (Malpighia 
emarginata D.C.), utilizando marcadores moleculares RAPD e características morfoagronômicas. Versão Brasileira Fruticultura, Jaboticabal - SP, v. 31, n. 1, 2009.

PÍPOLO, V. C.; PRETE, C. E. C.; GONZALEZ, M. G. N.; POPER, I. O. Novas cultivares de acerola (Malpighia emarginata D. C.): UEL 3 - Dominga, UEL 4-Lígia E UEL 5- Natália. Revista Brasileira de Fruticultura, Jaboticabal, v.24, n.1, 2002.

RITZINGER, R.; SOARES FILHO, W. S.; OLIVEIRA, J. R. P. Variedades e melhoramento. In: RITZINGER, R.; KOBAYASHI, A. K.; OLIVEIRA, J. R. P. A cultura da aceroleira. Cruz das Almas: Embrapa Mandioca e Fruticultura, 2003.
SALUNKHE, D. K.; DESAI, B. B. Postharvest Biotechnology of Fruits. Boca Raton: CRC Press, v. 1, 1984.

SANTOS, A. R. L. dos; REINHARDT, D. H.; SILVEIRA, W. R.; OLIVEIRA, J. R. P.; 218 CALDAS, R. C. Qualidade pós colheita de acerola para processamento, em função de 219 estádios de maturação e condições de armazenamento. Revista Brasileira de Fruticultura, Jaboticabal, v.21, n.3, 1999.

STROHECKER, R.; HENNING, H. M. Analisis de vitamina: métodos comprobados. Madrid: Paz Montalvo, 1967. 